\title{
Reflexões Étnicas Sobre o Processo Formativo a Partir de uma Perspectiva Psicológica
}

Resumo: Neste trabalho, realizou-se uma releitura do percurso conceitual traçado pela Antropologia e Pedagogia a partir de uma perspectiva psicológica, a fim de efetivar análise das relações étnicas no processo educativo.

Palavras-Chave: Universitário negro, etnocentrismo, classificação étnica.

Abstract:In this work, we did a new read of the conceit course traced by the antropology and pedagogy, from a psicólogy perspective, with the intention to make a analyse of this ethnic relationship of the educative process.

Key Words: Universitarian black, ethnocentracism, ethinic racial classification.

\section{Gerson Alves da Silva Júnior}

\section{Acadêmico do $5^{\circ}$ ano do curso de graduação em Psicologia. \\ Desenvolve pesquisa no Núcleo de Estudos Afro-brasileiros da Universidade Federal de Alogoos.}

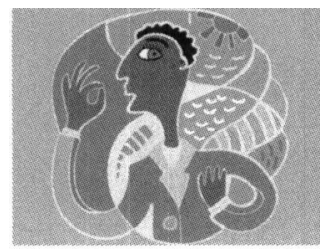

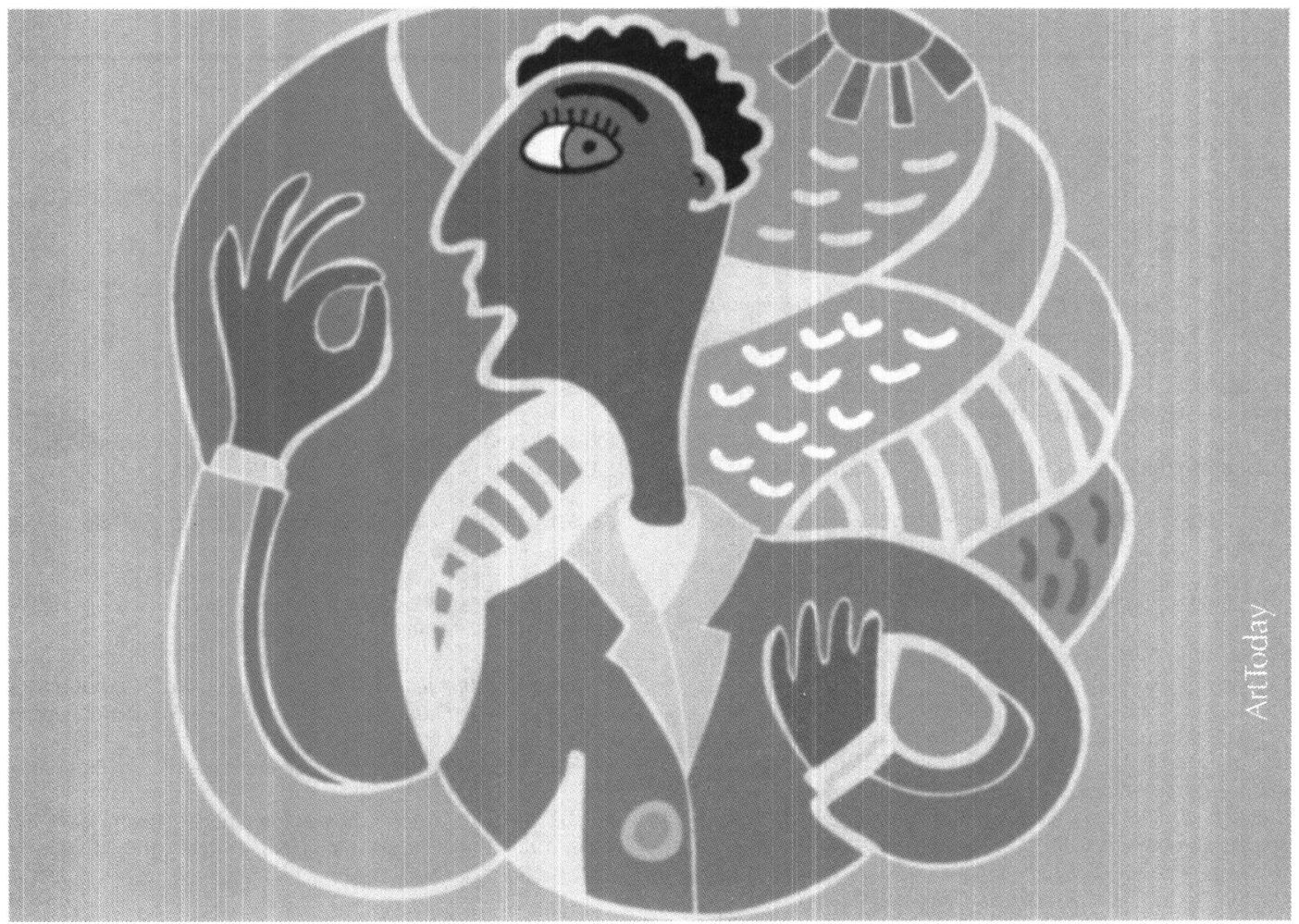

Durante o ano de 2000, ingressei num projeto de pesquisa, do Programa Institucional de Bolsas de Iniciação Científica (PIBIC), intitulado: "EscoOlarização em Preto e Branco ou Multicolorida? Trajetórias Escolares de Universitários Negros em Alagoas". O projeto abordava a problemática racial de nossa sociedade dando enfoque aos afrodescendentes. Até então, não havia trabalhado com a temática do negro em nosso contexto, mas, antes disto, havia me colocado à disposição do Conselho Indigenista Missionário (CIMI) como voluntário nos trabalhos que esse órgão desenvolvia.
Sob a orientação de alguns missionários do CIMI, desenvolvi um trabalho que chegou a ser contemplado nacionalmente. Entretanto, o Núcleo de Estudos Indígenas da universidade à qual pertenço, por ser pouco estruturado, não pôde oferecer orientação para o desenvolvimento de pesquisas que observassem o fenômeno étnico a partir de uma perspectiva psicológica.

Foi nesta ocasião que entrei em contato com o Núcleo de Estudos Afro-Brasileiros (NEAB), da Universidade Federal de Alagoas, no projeto 
supracitado, pois dessa forma não me distanciaria por demais de estudos que tinham como tema central as relaçōes étnicas. Todavia, ainda enfrentei algumas dificuldades, visto que meu orientador possuía formação em Filosofia e atuava na área de Pedagogia.

Porém, os esforços de meu orientador em buscar textos da área de Psicologia e estabelecer contato com outros profissionais que abordavam a temática dos afro-descendentes supriram em grande parte as necessidades que possuía para poder melhor me situar na pesquisa.

Assim sendo, realizamos a referida pesquisa, que nos ofereceu subsídios para a produção deste texto. $\mathrm{Na}$ realidade, passo a apresentar sucintamente os resultados e discussões dessa pesquisa que visava, por meio de processos rememorativos em entrevistas, a partir de um referencial bejaminiano $(1994)^{2}$, a reconstruir a trajetória formativa de alguns universitários afrodescendentes, a fim de pôr em evidência possíveis conflitos decorrentes da condição étnica, para daí então propor uma reflexão crítica em torno da sistematização curricular dos processos formais de ensino.

A nossa perspectiva teórica-metodológica partiu do pressuposto de que o objeto de estudo em questão requeria um duplo olhar, um olhar articulado através de distintas lentes - teleobjetiva, que possibilita registrar detalhes a longas distâncias e grande angular, pela possibilidade de reproduzir amplitude de campo. A nossa abordagem teve como objetivo apreender, de maneira relacional, a manifestação macro-micro social em nosso objeto. Para tanto, foi necessário, por um lado, evitar que categorias descontextualizadas e macroanalíticas amordaçassem o objeto; por outro, não permitir que as configurações micro-relacionais fossem apreendidas como uma espécie de seres incomunicáveis.

Buscamos, através de três diferentes movimentos, construir diferentes troncos nodais ${ }^{3}$. Um primeiro, de abertura empírica, ou seja, acesso multidimencional à realidade; um segundo, de síntese, em que através do entrecruzamento e da sistematização de dados, de informações, fomos construindo os troncos nodais; por último, $\mathrm{o}$ momento que denominamos de catarse cognitiva, ou melhor, quando penetramos no tronco nodal a fim de indicar questōes nucleares, desconstruindo e desvelando nós, imaginando e visualizando possíveis cenários e horizontes teóricopráticos com o objetivo de provocar a construção de uma abordagem educativa crítica que incorpore dinamicamente novos aspectos em suas formulaçóes. Vale ressaltar, entretanto, que esses momentos não foram concebidos de maneira estanque, mas em relação e diálogo.
No desenvolvimento de nossa pesquisa, tínhamos em mente ampliar e incorporar novas reflexões, posicionamentos teórico-metodológicos em torno da relação que estávamos buscando estabelecer entre produção cultural escolar e as experiências formativas de universitários negros. Contudo, na medida em que tínhamos como ponto de partida a escola como instituição de produção cultural $\left.\right|^{5}$, partimos do continuum PRODUÇÃO-REPRODUÇÃO ${ }^{6}$, pois tínhamos como pressuposto a dinamicidade inerente ao processo de produção cultural.

Nossa apreensão desse processo se contrapôs às perspectivas essencialistas, estáticas da cultura, que a vêem como um produto pronto, acabado. Essa concepção entende, por exemplo, a curricularidade como a organização de conhecimentos sistematizados socialmente e necessários ao processo de socialização dos indivíduos. $O$ processo formativo se limita a transmitir esse produto acabado, não conflitivo.

Em sintonia com a abordagem de Silva (1997), que concebe a cultura, sobretudo, como atividade, ação, experiência que se faz no interior de uma teia de significados, é que buscamos apreender as tramas formativas presentes nos processos formais de aprendizagem desses universitários.

Após a abertura empírica inicial, antes da realização das entrevistas, deparamo-nos com um problema. Tal problema seria inexistente se tivéssemos que realizar uma pesquisa com a mesma natureza desta nos EUA ou na Europa. Trata-se da definição de nosso objeto de estudo: o universitário negro ?

Essa preocupação inicial levou-nos à produção de um pequeno artigo que aqui sintetizo e apresento sob a forma de tópico inicial. Essa produção inicial serviu-nos de base e guia para a definição dos nossos sujeitos de pesquisa.

No total, realizamos sete entrevistas individuais e uma coletiva, que nos ofereceram rico material para análise ${ }^{8}$. As entrevistas individuais seguiram apenas um eixo norteador direcionado para a trajetória formativa dos sujeitos. Detivemo-nos, dentro desse eixo, em três focos formativos, a saber: família, sociedade e escola. A coletiva teve como objetivo esclarecer alguns pontos obscuros das entrevistas individuais e envolver um pouco mais nossos entrevistados com a pesquisa e a questão do negro no Brasil.

No último momento da pesquisa, pudemos ter um novo vislumbre da questão racial e da educação em nosso contexto. São justamente esses vislumbres que passo a apresentar.

Inicialmente, apresento a dificuldade do sistema de classificação racial brasileiro. Posteriormente,
1 Órgão ligado à lgreja Católica.

2 Para Benjamim (1994), nada do que aconteceu pode ser considerado perdido para a História. Ora, ele chamou a atençāo para elementos que podiam ser negligenciados, $e$ assim fadados ao esquecimento.

3 Espécie de pontos nucleares em que vários fatores se articulam, coordenam, assumem determinada forma, um espaco para o qual converge um feixe de aspectos economicos, sociais, politicos, culturais, emocionais, etc.

4 Aristóteles "foi o primeiro que o estendeu para designar também um fenômeno estético, isto é, aquela espécie de libertaçāo ou purificação que o homem experimenta por obra da poesia e em particular do drama e da música" (ABBAGNANO, 1982:113). Originalmente, ouso mais comum é no sentido médico de purificação. O sentido que estamos dando se aproxima da dimensäo estética e prazerosa do conhecer e desvendar nós.

5 Ver Jacyara Nasciutti em "A Instituição como Via de Acesso à Comunidade"

6 "Na verdade, o que quero é criticar uma concepção na qual a cultura aparece como um produto $e$ se abandona a explicação do modo pelo qual é produzida, perdendo-se assim toda possibilidade de uma análise frutifera da dinâmica cultual" (Durham, 1977:03). Essa forma de perceber a cultura dentro de um processo de produção histórico entra em conformidade com as proposiçoes de Lane (1998).

7 Acontece que, no Brasil, principaimente nos Estados com grande contingente de mesticos, é muito complexo o sistema de classificação racial (Ramos, 1957: 180). Dessa forma, para darmos inicio à nossa coleta de dados tivemos que fazer inicialmente um aprofundamento bibliográfico criterioso para podermos ter uma definição dos sujeitos que nos interessariam.

8 As entrevistas individuais foram gravadas e em seguida transcritas na íntegra para posterior análise. A entrevista coletiva nãofoi gravada, apenas foram notificadas algumas questöes relevantes. 


\author{
É bastante difícil o \\ estabelecimento de \\ critérios que \\ permitam \\ classificações, visto \\ que classificar, \\ categorizar, \\ enquadrar etc., são \\ parâmetros que \\ exigem mais que \\ capacidade de \\ diferenciação, \\ exigem uma certa \\ descoberta de \\ essências.
}

9 Filosoficamente, a essência determina o ser, fálo ser isso e não aquilo. Cf. MONDIN, Batista. Curso de Filosofia, vol $1,8^{\circ} \mathrm{ed}$. Sāo Paulo: Paulus, 1997.

10 Representaçöes mentais (RM) é um conceito filosófico que passou a ser uma realidade mensurável na área da neuropsicologia. É por meio das RM que o cérebro organiza e forma suas informaçöes.

11 Cientificos.

12 Estamos usando o termo negritude como sinônimo de negro neste texto. no tópico dois, exponho algumas questões relativas ao racismo de nosso contexto social. Nesse tópico dois, apresento o racismo como substrato ideológico que motiva e determina os comportamentos discriminativos que são tratados de forma expositiva no tópico três.

Como meio de comprovação da argumentação referente aos processos racistas de nosso contexto é que apresentamos, no terceiro tópico, os resultados de nossa pesquisa, que nesse caso se configurariam realmente no plano comportamental, influenciando outras questões como a auto-estima, sendo, dessa maneira, pertencente ao campo psicológico.

Nesse sentido, espero estar considerando a pluralidade étnica de nossa sociedade esforçando-me por contribuir enquanto futuro profissional de Psicologia para a superação dos desafios que essa profícua ciência enfrenta em nossa sociedade por, muitas vezes, não haver estudos direcionados aos processos étnicos-culturais para a compreensão global do sujeito.

\section{Classificação de Negros no Brasil}

O que é ser negro no Brasil? Essa pergunta, aparentemente fácil de responder, é bastante difícil de ser precisada. Embora pudéssemos pensar que é fácil diferenciar negros de brancos, esse raciocínio não corresponde à realidade se pararmos para refletir em que nos baseamos para fazer determinadas classificações.

É bastante difícil o estabelecimento de critérios que permitam classificaçôes, visto que classificar, categorizar, enquadrar etc., são parâmetros que exigem mais que capacidade de diferenciação, exigem uma certa descoberta de essências.

Filosoficamente, essência é aquilo que faz o ser ser o que é ${ }^{9}$, e a classificação - seja ela qual for sempre consiste na crença da descoberta de um ou alguns elementos comuns entre os seres de um conjunto. Dessa maneira, em determinado ponto, classificar e descobrir essências se torna a mesma coisa.

Mas, na verdade, a descoberta dessas características comuns não é uma tarefa tão fácil se considerarmos a dificuldade da existência de dois elementos idênticos na natureza. Assim, verificamos que os sistemas classificatórios tomam apenas características aproximadas. Então, fica difícil estabelecer o limite preciso de diferença e semelhança que irá servir de critério para a classificação de seres. Entretanto, em determinados pontos, temos a necessidade de classificar, até porque tal processo é algo natural, necessário na construção de representaçōes mentais $^{10}$ e de saberes sistêmicos ${ }^{11}$.
São as classificações que nos permitem, de certa forma, uma orientação no rico mundo diversificado em que estamos inseridos. Mas, cada vez mais, convencemo-nos de que a classificação em si existe apenas como uma formatação ou uma padronização que se baseia em princípios ideológicos elaborados a partir de perspectivas diferentes do mundo.

Muitas vezes, esses princípios ideológicos conseguem atingir e influenciar uma enorme quantidade de indivíduos; conseqüentemente, teremos uma "comum-unidade" na forma de conceber determinados aspectos da vida e do mundo. Havendo uma uniformi-dade no modo de conceituar, teremos uma classificação conforme o grupo considerado.

Assim, podemos expor agora a dificuldade de se classificar grupos raciais no Brasil. Conforme nosso desenvolvimento, é difícil haver universalidade no conceito de negritude ${ }^{12}$. Isto se deve ao fato de cada povo possuir suas particularidades históricas, que proporcionaram diversas formas de visualizar o mundo - lembremos que, nessa perspectiva, a ideologia fundamenta a classificação.

Sabemos que as classificaçōes étnicas/raciais, em si, dependem de determinadas características comuns entre indivíduos; essa comunhão de características será encontrada e elencada conforme a perspectiva ideológica de cada grupo. Dessa maneira, um mesmo objeto pode ser classificado de várias formas a depender da ideologia que fundamenta essa classificação.

A exposição que faremos a seguir, do sistema classificatório brasileiro, se baseia fundamentalmente em dois autores: Schwarcz (1993) e Munanga (1996), pois esses autores se utilizam de uma linguagem que parece ser mais acessível ao objeto do qual tratamos.

Conforme a análise de Schwarcz (1993), o período que decorre de 1870 a 1930 é um período fundamental para a formação da ideologia que tratamos, pois, segundo a autora, é nesse período que há uma cristalizaçāo e definição dos centros de saberes no Brasil e uma série de transformações sócioeconômicas, como a Proclamação da República, por exemplo. Com relação aos centro de saberes, Schwarcz sustenta:

“(...)[Tinham] a firme intenção de estabelecer no país instituições centralizadoras que reproduzissem de forma perfeita o antigo domínio colonial [europeu]".

Todavia, esse projeto colonial não foi de todo perfeito, pois as teorias européias, tais como o 
evolucionismo, o darwinismo social e outras, embora tenham sido empregadas e incorporadas no construto ideológico brasileiro, não o foram de forma mecânica, isto é, essas teorias foram apropriadas, segundo a autora, com originalidade pelos estudiosos brasileiros (Schwarcz, 1993:23-66).

Schwarcz insinua que os teóricos brasileiros vinham de uma realidade miscigenada, misturada, e por isso não podiam concordar plenamente com as idéias de degenerescência de raças e outras.

Schwarcz aponta que todas essas elaborações culminam num processo chamado ideal de branqueamento. $\mathrm{O}$ ideal de branqueamento consistia na supervaloração da produção das raças brancas, na injeção de sangue europeu e na promoção de uma maior fertilidade dos grupos brancos, dentre outros pontos.

O ideal de branqueamento surge como resultante e em conformidade com a realidade miscigenada do Brasil. Como era impossível formar uma nação (identidade nacional, identidade comum) branca (civilizada) pura, dada à mestiçagem existente, aponta-se à miscigenação como solução para o problema da unidade nacional ${ }^{13}$. Entretanto, acreditava-se que, se fosse colocado muito sangue autóctone e de origem africana na mistura, se formaria um povo selvagem ${ }^{14}$. Porém, sendo a miscigenação com esses povos ("inferiores") um fato consolidado e impossível de ser negado, restava apenas o controle dessa miscigenação, através do branqueamento.

Entender todo esse processo histórico é de fundamental importância para compreendermos o sistema de classificação racial no Brasil, pois, conhecendo esse processo, entenderemos porque o brasileiro esconde sua negritude. $O$ fato de esconder a negritude não se dá apenas por ter sido a raça negra escravizada, mas também por ter surgido uma forte ideologia que exaltava a miscigenação fundamentada no branqueamento.

Conforme Munanga (1996), como era e continua sendo elevadíssimo o número de sujeitos mestiços, não se poderia ignorar ou menosprezar esse contingente tão alto de indivíduos; então, acreditava-se que se resolveriam, exaltando-se a mistura ${ }^{15}$ racial, dois problemas de uma única vez: 1) as diferenças culturais e 2) o problema da degenerescência.

É nesse contexto que a classificação étnica no Brasil, segundo Munanga, (1996) com apoio em Maggi, toma dois pólos: um positivo e outro negativo. $O$ pólo positivo se caracteriza pelo fato de ser, ou de se aproximar, mais do claro, ou seja, está amparado pelo ideal de branqueamento. $\mathrm{O}$ pólo negativo consiste no fato de ser escuro ou de se aproximar fenotipicamente das raças consideradas inferiores (Munanga, 1996:190).

O fato de o brasileiro esconder sua negritude é evidente; para comprovar isso,basta o levantamento feito pelo historiador Clóvis Moura, que demonstra a citação de 136 diferentes classificações de cores feitas pelos brasileiros quando inquiridos a respeito de sua $\operatorname{cor}^{16}$. Essa possibilidade de classificar indivíduos de determinada origem numa outra categoria étnica é possível dentro do sistema classificatório étnico brasileiro, que se diferencia do de outros países ${ }^{17}$. Conforme a análise que se vinha fazendo, essas diferentes formas de classificar (entre diversos países) se devem a realidades históricas diferentes.

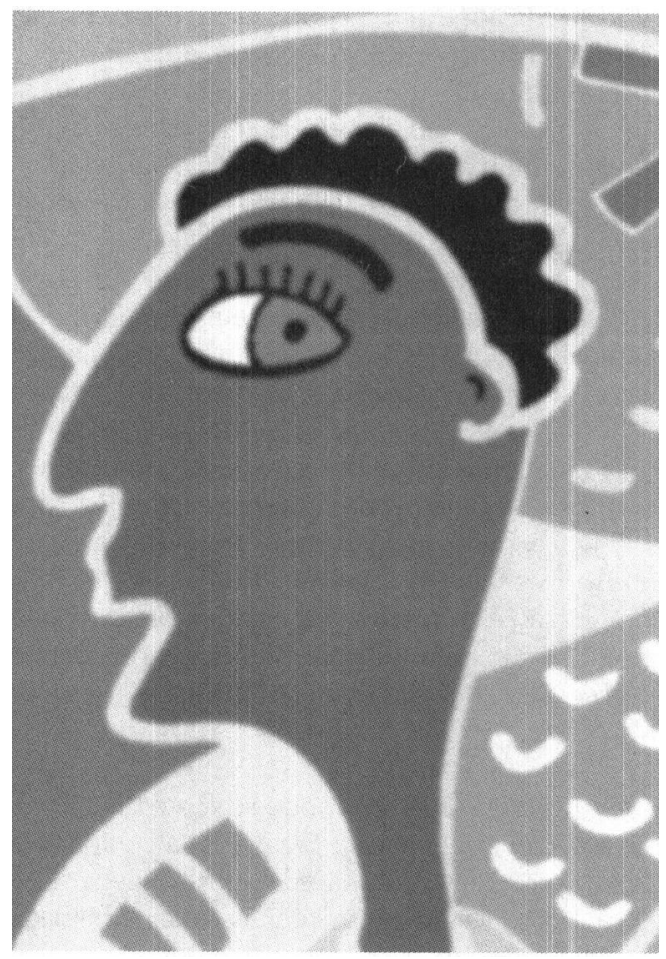

No Brasil, devido aos eventos históricos, ou seja, devido à realidade social, econômica, cultural e intelectual da época ${ }^{18}$, a classificação não foi feita tomando por base a origem ou o sangue do indivíduo, mas conforme o fenótipo do sujeito. A classificação racial no Brasil é uma classificação cromática, isto é, baseia-se na cor da pele.

Entretanto, o sistema de classificação brasileiro, na verdade, não é único. Segundo Munanga, o sistema de classificação utilizado por cientistas sociais e ideólogos negros é um, e o sistema utilizado na "auto-representação popular" é outro. O primeiro baseia-se na: "(...) polarização preto/

13 Segundo Munanga (1996), existia uma preocupação com a unidade nacional, pois teoricamente esta corria riscos, devido à diversidade cultural que havia durante o processo de formação nacional.

14 As teorias cientificas da época consideravam essas raças menos evoluidas.

15 Vale ressaltar que essa exaltação da miscigenaça so ocorre quando esta é direcionada para a branquidade rque sinônimo de civilização evoluçāo, dentre outras coisas). Dai surge o porquê de o mestiç brasileiro buscar ao máximo se aproximar do padrāo étnico branco, ao passo que esconde sua negritude.

160 levantamento foi realizado após o censo de 1980 .

17 Munanga (1996:184-185) nos apresenta dois exemplos do classificaçöes diferentes: a classificação dos Estados Unidos e a da África do Sul. O primeiro exemplo classifica conforme a origem do individuo 7 , ou seja. mesmo que o individuo se apresente fenotipicamente branco $e$ que tenha maioria branca em sua ascendéncia, basta-lhe um linico antepassado, por mais remoto que seja, para que este seja visto (classificado) como negro. o segundo exemplo, o da Áfica do Sul, também apresenta um sistema semelhante, isto $\dot{\varepsilon}$. a classificaçāo também é feita de acordo com a origem do individuo. Só que, diferentemente do sistema americano. que é dualista, o sul-africano abarca uma categoria intermediária. Na Africa do Sul existem três categorias: branca (European), negra (bantou) $e$ mestiça (coloured)

180 elevado contingente de mestiços, influências de ideologias européias que supervalorizavam o branco, necessidade de unidade nacional, etc. 
branco ou negro/branco, enquanto [o segundo, utiliza-se del (...) um sistema relacional baseado no binômio claro/escuro."

Na classificação (auto-representação) popular, segue-se uma gradação de tons, ou seja, vai-se do mais escuro ao mais claro de forma compassada a fim de se aproximar ao máximo do padrão étnico branco, permitindo inclusive a relocação dos sujeitos de um grupo étnico para outro. Nesse sistema classificatório, no extremo do escuro se tem o negro (pólo negativo), no outro extremo se tem o branco (pólo positivo). Essa classificação existe como uma forma de esconder a negritude ideal de branqueamento. Segundo Munanga "Dependendo do grau de miscigenação, o mestiço brasileiro pode atravessar a linha de cor e ser reclassificado na categoria "branca". Jamais poderá ser reclassificado como negro, salvo raras exceçōes, devidas notadamente à escolha individual por posicionamento ideológico. Seria o caso dos poucos mestiços politicamente mobilizados e que se consideram negros para forjar a solidariedade $\mathrm{e}$ a identidade política de todos os oprimidos" (Munanga, 1996:186).

Existe ainda uma variação no sistema classificatório brasileiro que, de certa forma, é uma flexibilidade dentro do próprio sistema, pois, conforme Munanga,

“(...) [Quando falamos de sistemas classificatórios, estamos nos embasando no] plano ideológico e coletivo e não [no] (...) periférico das relações interindividuais, pois, neste último, quando a competição é acirrada entre indivíduos mestiços $\mathrm{e}$ brancos, (...) o mestiço é simplesmente reduzido à expressão popular de 'neguinho metido' (Munanga, 1996:186).

Sintetizando o exposto, pode-se sustentar que a classificaçāo de negros no Brasil é feita conforme a cor da pele, desconsiderando-se as origens. Esse sistema classificatório permite uma certa mobilidade do sujeito dentro das categorias graduais claras e escuras. Em relaçōes interindividuais, esse sistema em determinadas condições é quebrado e pode-se classificar de outras formas (pela origem, por exemplo). Em nossa pesquisa, embasamo-nos na fenotipia associada à auto-identificação; assim, não corremos o risco de fugirmos do nosso objetivo de entrevistar universitários negros.

19 Esta abertura de interpretaçōes se chama polissemia.

20 Alguns cientistas especificam o termo como raça social a fim de cvitar confusóes. (etnia) dominante, ao passo que impedisse a tomada de consciência das classes (etnias) subjugadas (Munanga, 1996:188-193). Esse sistema "(...) é um sistema capaz de manter uma estrutura racista sem as hostilidades abertas encontradas em outros países". É nesse contexto que deve ser entendido o sistema de classificação étnica do Brasil e, conseqüentemente, a classificação de negros.

\section{O Racismo - Plano Ideológico}

Antes de adentrarmos no tratamento da questão da configuração do racismo no Brasil, faz-se necessário tecer algumas considerações a respeito da manifestação do fenômeno em si e do vocábulo utilizado para ilustrá-lo. Por isso, primeiramente, façamos uma breve reflexão sobre a capacidade que os símbolos lingüísticos (as palavras) possuem para comportar conceitos que têm o intuito de representar eventos da realidade.

$\mathrm{Na}$ verdade, de certa forma estamos dando um tratamento aos termos lingüisticos de significante. Um significante é uma expressão, um som, uma imagem ou qualquer impressão que é associada a outras impressões para a construção de seu significado (Skinner, 1957). Essa possibilidade de associações é infinita e por isso viabiliza uma indeterminação que proporciona várias interpretações para um único significante ${ }^{19}$.

Ressaltemos, ainda, uma diferenciação de conceitos. Trata-se de especificar o uso do termo representação social, que utilizamos como sinônimo de significado manifesto nos discursos para grupos ou sujeito determinado (Lane, 1998). Portanto, diferencia-se, nesse contexto, do conceito de significante, que faz referência a toda possibilidade de sentidos que um termo possa adquirir ou expressar.

Diante do exposto, passemos à análise do termo racismo. O termo racismo deriva da palavra raça, e é um significante tão amplo como o seu significante de origem. O significante raça, utilizado como classificação, conforme Cashmore (2000), foi empregado historicamente pelo menos em quatro sentidos, a saber: subespécie, espécie, nação e marcador de característica física. Neste último sentido, o termo raça "(...) pode significar um grupo de pessoas socialmente unificadas numa determinada sociedade em virtude de marcadores físicos como a pigmentação da pele (...) e coisas do gênero". Os cientistas sociais, na sua maioria, usam o termo apenas nesse quarto sentido ${ }^{20}$.

Compreendendo os sentidos do significante raça, podemos afirmar que a palavra racismo também é usada com vários sentidos. Banton (2000) afirma que, até o final da década de 1960, a maior parte
Concluindo, conforme o apresentado, todo sistema de classificação está alicerçado em um plano ideológico, e este plano, por sua vez, é constituído historicamente. No Brasil, houve a necessidade da formação de um sistema ideológico profundamente assimilativo que abarcasse a diversidade étnico-cultural deste $\mathrm{e}$, ao mesmo tempo, escamoteasse as articulações da classe 
dos manuais e dicionários conceituava racismo como doutrina, dogma ou ideologia, sendo que a essência dessa doutrina era que a raça determinava a cultura, e que havia certa hierarquização entre as raças. Depois a palavra foi usada num sentido ampliado, incorporando práticas, atitudes e crenças. $O$ termo racismo também foi utilizado para nomear o complexo histórico gerado a partir da expansão do capitalismo aqui nas Américas, onde se necessitou da exploração da mão-de-obra africana, criando-se todo um complexo para facilitar a exploração desta; a esse complexo diversas obras acadêmicas nomearam racismo.

Embora não haja razão para a palavra racismo não ser empregada em diferentes sentidos, nos últimos tempos ela foi usada de tantas maneiras que pode até perder seu valor como conceito. Por isso, muitos tentaram pôr limites e conceituam racismo como uma ideologia interligada ao desenvolvimento das teorias raciais do século XIX (onde as características biológicas determinavam as características culturais e psicológicas) ${ }^{21}$. Como diversos aspectos das teorias raciais que embasam o racismo não encontram mais fundamentação científica, tais reivindicações foram deixando de ser usadas; por isso, a palavra racismo, conforme esses teóricos, vem caindo em desuso (Banton, 2000:460).

Outros, porém, concebem o racismo de forma diferente, porque segundo eles, o racismo se caracterizaria pelo tratamento diferenciado que alguns grupos manifestariam a outros pelo fato de atribuirem uma relação determinista entre um grupo e as supostas propriedades deste (Banton, 2000:460).

Na atualidade, atesta Pereira (1996:18), o conceito de racismo fica melhor compreendido como uma manifestação do etnocentrismo. Nessas manifestaçōes, grupos formulam ideologias e políticas que justificam tratamentos diferenciados.

Entretanto, em todas essas formas de compreender o racismo, muitas complementares umas das outras, temos o significante raça, independente do sentido aplicado, como ponto central dessa problemática. Assim, embora seja perigoso, podemos apresentar um conceito amplo de racismo, que incorpore o seu conceito primevo mas que não negligencie as atuais compreensões do termo. Dessa forma, racismo seria todo e qualquer processo ideológico que, tomando por base a compreensão de raça, permite a manifestação de conflitos ou tratamentos diferenciados.

No Brasil, sem muitas dificuldades, encontramos a negação por grande parte de sujeitos da existência do racismo. Quando se admite sua existência, se afirma logo em seguida: “mas não é tão maléfico como nos outros países" ". Há em nosso país a crença na convivência harmônica entre diferentes raças.

"Essa crença, fortemente consolidada no imaginário nacional e que a historiografia e a ciência deram status de verdade, veio pouco a pouco, em ritmo político, se consolidando no cansativo slogan (...) de o país da democracia racial". (Pereira, 1996:2021)

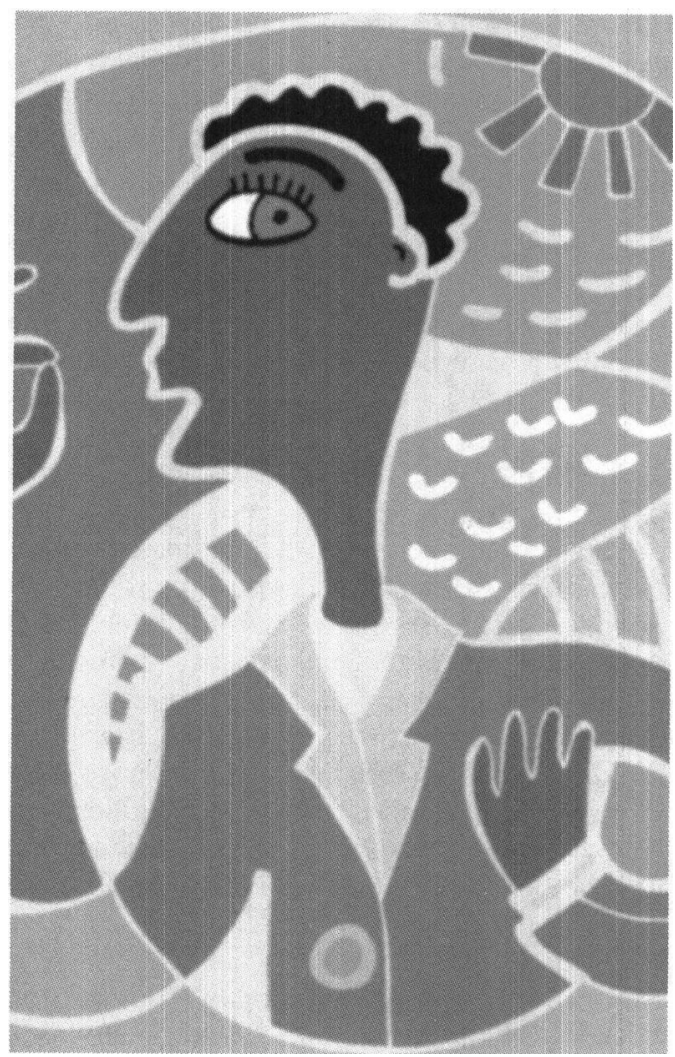

O racismo quando admitido, no Brasil, nāo é encarado como algo preocupante como nos demais países multirraciais. Parte desse processo pode ser atribuído às elaborações de teóricos como, por exemplo, Gilberto Freyre, que disseminaram a idéia de uma democracia racial, onde se coloca que a miscigenação em nosso país foi tamanha que o brasileiro que não for mestiço no sangue é na alma (Freyre, 1930). Essa crença do brasileiro ser um pouco de tudo (ideologia assimilativa, Munanga, 1996) alimenta um pensamento que, de certo modo, impede identificações étnicas particulares e por isso pode-se erroneamente concluir que é impossivel haver racismo no Brasil.

Desenvolveu-se no Brasil também a idéia de uma raça brasileira (Darcy Ribeiro, 1987 e 1995) fundada na mestiçagem. Essa formulação de raça brasileira faz com que seja negada, de certo modo,

\section{"o conceito de \\ racismo fica melhor compreendido como uma manifestação do etnocentrismo".}

Pereira

21 Portanto, nesse sentido, racismo como conceito “(...) distinguiria as reivindicaçôes e argumentos que asseveram explicitamente que as características biológicas das pessoas sāo sinais de suas características psicológicas e culturais" (Banton, 2000:460).

22 Sustenta-se assim que a análise do "(..) significado da forma ideológica chamada racismo deveria ser subordinada a uma consideracão de sua estrutura" (Banton, 2000:460).

23 Acadêmico de Pedagogia 
24 Nâo haveria diversas raças, mas apenas uma: a mestiça (Ortiz, 1994:41).

25 Provocando a idéia de aceitaçäo incondicional do outro.

26 Tal associação gerou uma incongruência que, muitas vezes, provoca diversas confusōes entre o conceito primevo do termo e os demais sentidos que este tomou devido às suas manifestações particulares.

27 Além disso, esse racismo é enormemente dificil de ser combatido em nossa sociedade por ele se apresentar no inconsciente coletivo e nāo de forma declarada (Munanga, Revista Veja, 1996).

28 As primeiras podem causara morte fisica e as últimas a morte do sujeito enquanto ser que realiza e contribui com o mundo. Aqui, cabe o argumento cristāo que afirma que "muitos que morreram podem continuar vivos e muitos dos que estāo vivos, ainda que vivos, podem estar mortos". a plurietnicidade do nosso povo e, da mesma forma do pensamento anterior, leva a conclusão equivocada da não-existência de racismo no Brasil. $^{24}$

Entretanto, embora a mestiçagem seja uma realidade em nosso país, não é suficiente para a construção da argumentação da impossibilidade de haver racismo aqui, pois existem diferentes sentidos para o significante raça, e mesmo que alguns teóricos continuem fazendo formulaçōes que negam, de certa forma, que o Brasil seja um país multirracial, para a população em geral existem diferentes raças, sendo o termo raça aqui empregado na maioria dos casos como marcadores de características físicas.

Como bem atesta Munanga (1996), a classificação racial brasileira é uma classificação cromática (fenótipa). Esse tipo de classificação permite que parentes próximos possam ser alocados em raças diferentes.

Existindo essa forma de classificação racial, não haveria razão para não admitirmos a possibilidade de conflitos entre esses grupos. Mas, mesmo assim, tais conflitos e disputas raciais podem ser negados por diversas razões. Uma delas é justamente o fato de acreditar que existem muitos laços de parentesco entre os sujeitos de raças diferentes, o que impediria os conflitos. Outra razão é a ideologia profundamente assimilativa do nosso povo, que incorpora e evidencia elementos das diferentes culturas $^{25}$. E, enfim, por falta de objetividade, ou melhor, de limites precisos da classificação racial brasileira.

Conforme o próprio Munanga, a questão da ideologia assimilativa não impede a manifestação do racismo, mas apenas permite a manutenção de uma estrutura racista sem as hostilidades dos demais países, pois embora a cultura brasileira seja assimilativa, possui um eixo norteador branco (entendido como positivo). As outras duas razões, de certa forma, dizem respeito à questão da posição do mestiço, e, segundo o mesmo autor, nas disputas pessoais acirradas o mestiço é rapidamente classificado como negro (encarado como sendo negativo).

Tudo isso deveria ser suficiente para afirmarmos a existência do racismo em nosso país, mas, mesmo assim, encontra-se forte negação deste (Pereira, 1996: 18 -21).

Se tomarmos o conceito de racismo que expusemos acima, veremos que o racismo em nossa sociedade é tão presente como nas demais. Acontece apenas que a própria formação histórica do nosso povo permitiu a consolidação de um racismo diferente, mascarado, inteligente, pois, como veremos, manifesta-se nas brincadeiras, por vezes nos olhares e, com menor intensidade, no trato com as pessoas. Por essa razão, apresentaremos ainda um outro motivo para a negação do racismo em nosso país: o racismo é negado mais pela polissemia do significante racismo e não tanto pela manifestação do fenômeno em si, pois, como veremos, embora o racismo no Brasil possua características particulares, ele não foge do conceito maior de racismo citado.

Acontece que o termo racismo se vulgarizou no Brasil a partir de 1935, conforme atesta Ávila (1978), na época do nazismo. Daí, não foi difícil associar racismo a atos de violência física extremados, a intolerância e genocídios. Por isso, de certa forma, falar de racismo no Brasil é invocar a lembrança de crimes bem diretos e objetivos contra grupos raciais bastante definidos. Portanto, ao confrontar o emprego do termo no exterior com a realidade interna das relaçōes raciais em nosso país, provocava-se uma incompatibilidade com reflexos até os dias atuais, que culminou na negação do racismo ou na afirmativa de que "o racismo no Brasil não é tão maléfico como nos demais países", ou seja, a associação de fatos que os sujeitos da sociedade brasileira fizeram com o termo racismo ofuscou e ofusca o vislumbre desse fenômeno em sua realidade ${ }^{26}$.

As características singulares do racismo em nossa sociedade fazem dele um racismo mais inteligente, mais elaborado, visto que este se manifesta principalmente nas brincadeiras, o que lhe confere certa subjetividade e possibilidade de ser interpretado de diversas formas, inclusive como não sendo racismo ${ }^{27}$.

Antes de prosseguirmos, cabe uma última reflexão. Trata-se das colocações que afirmam não ser o racismo preocupante em nosso contexto, tendo em vista que ele não é um racismo que se manifesta na violência física, não é um racismo institucionalizado, não é declarado, nem amparado por leis. Essas colocaçōes insinuam que o racismo à brasileira não fere, nem machuca os que sofrem seus efeitos. Entretanto, conforme constatado na pesquisa, o racismo em nossa realidade é capaz de desestruturar a personalidade do sujeito, deixando-o envergonhado de sua própria imagem, provocando-lhe uma crise de identidade. Tudo isso faz com que os sujeitos possam se tornar inseguros, temerosos, inibidos, revoltados etc. Diante disso é que colocamos a grande reflexão filosófica sobre o que é preferível: as amarras e as torturas físicas, ou as amarras e as torturas mentais ${ }^{28}$. 


\section{A Discriminação - Plano Comportamental}

Após as considerações feitas em torno do termo racismo, podemos agora analisar melhor esse fenômeno em nosso contexto.

Antes, porém, fiquemos informados de que a discriminação racial é o meio pelo qual o racismo se manifesta e se torna concreto, pois se evidencia no comportamento. Qualquer atitude que tenha por base o racismo, esse entendido enquanto ideologia, será sempre caracterizada como discriminação. Discriminar significa diferenciar e especificar. Assim sendo, tratamentos (ou outros processos) diferenciados que tomem por base conceitos raciais são, de forma geral, uma discriminação racial ${ }^{29}$.

Embora haja no Brasil uma certa crença na nãoexistência do racismo, por meio da sua concretização, a discriminação, podemos verificar sua existência. Todavia, não negamos uma configuração diferente desse racismo na sociedade brasileira.

Existem duas categorias de discriminação. A primeira é a que abarca o conjunto de fatores sociais que impedem ou dificultam o acesso de determinados indivíduos a certas instituições ou direitos sociais, e sua análise se configuraria no campo da Sociologia.A segunda envolve o conjunto de comportamentos inter-relacionais que implicam diferentes formas de agir e se portar devido a fatores ideológicos. No entanto, na sociedade brasileira, essas fronteiras não são tão nítidas, muitas vezes se produzem simultaneamente, interpenetrando-se dinamicamente. Nesta segunda, a análise pertenceria ao campo psicológico.

Neste caso, tratei especificamente da discriminação racial na categoria de comportamentos interrelacionais (campo da Psicologia), mas não deixei de constatar, por meio de análise de outras pesquisas, a manifestação do racismo, em nossa sociedade, na categoria de dificuldades de acesso.

Sobre esta última categoria, é bastante interessante a pesquisa realizada pelo Professor Marcelo Paixão", intitulada "Os Indicadores de Desenvolvimento Humano (IDH) como Instrumento de Mensuração de Desigualdades Étnicas: O Caso Brasil". Nesse estudo, o professor chega a importantes resultados, onde apresenta uma diferença diametral entre o "Brasil negro" (afro-descendente) e o "Brasil branco" ${ }^{31}$, onde o negro ocupa escalas sociais inferiores.

Mas, como frisei, este trabalho se direciona para a esfera da discriminação racial no plano dos comportamentos inter-relacionais. Sobre essa categoria desenvolvi este trabalho, tomando como eixo o processo formativo dos universitários que entrevistamos.

Os entrevistados, embora não existam dados estatísticos precisos, são claramente uma minoria étnica em nossa universidade ${ }^{32}$. Portanto, de certa forma, são um grupo seleto do já seleto grupo universitário de nosso Estado e do nosso país ${ }^{33}$.

Entretanto, mesmo sendo um grupo 'privilegiado', este não deixou de compartilhar diversos processos discriminatórios comuns à sua etnicidade. A condição de pertencer a um grupo seleto não elimina as experiências de discriminação racial ${ }^{34}$.

Todos os entrevistados relataram pertencer à classe média baixa. Também nos seus relatos constatamos que os mesmos vivenciaram situações de discriminação racial. Um outro aspecto comum, percebido a partir das entrevistas, foi o da nãopercepção das condutas discriminatórias por parte dos demais sujeitos não-discriminados, ou a atribuição de outras razões a esses comportamentos.

“(...) pobre é sinônimo de negro, ou negro é sinônimo de pobre" (Helena ${ }^{35}$ ).

As condutas discriminatórias, conforme relatos, não se apresentavam, na maioria das vezes, por parte do corpo docente, mas nas bricadeiras e tratamentos manifestados pelos companheiros escolares ou amigos de bairro.

"No primeiro grau, no primeiro grau teve [discriminação], com os amigos, com os colegas de sala, mas assim com professor não. Nem no segundo grau, nem agora (Helena).

Entretanto, não pode ser negligenciado o aspecto eurocêntrico dos currículos escolares, que apresenta o negro apenas no trato das relaçóes escravistas no Brasil colonial. Reduz-se o estudo do continente africano e do negro a apenas alguns capítulos de História e Geografia, e ainda assim se apresentam visões deturpadas e estereotipadas.

"A coisa era mais ou menos como: "nêgo preguiçoso, índio preguiçoso, que não trabalharam nada, não fizeram nada'. Isso de alguns professores, outros professores já colocavam que: 'não, o papel do negro no Brasil construiu muita coisa, trabalhou muito, vindo a força da África para cá. Não queria vir, mas já que veio, chegou aqui trabalhou e tal'. Então tinha essas duas visões e eu, não só eu, acho que todos os alunos ficávamos meio que perdidos nessas duas visões da $5^{\underline{a}}$ a $8^{\underline{a}}$ série" $^{\prime \prime}$ (José ${ }^{\text {bh }}$ )
29 Em sintese a concretizacão do racismo, que éuma ideologia. ocorre através da discriminaçào.

30 Coordenador do Projeto Brasil 2000 - Novos Marcos para as Relacóes Raciais da Federaça de Órgãos para Assistencia Social e Educacional (FASE). professor do Departamento de Economia da UFR/.

31 os estudos de paixão baseiam-se nos relatórios de Desenvolvimento llumano das Organizaçoes das Naçós Unidas (ONU) de 1999. No IDH (Indice de Desenvolvimento Humano), conforme esse relatório, o Brasil se encontrava em 1997 na $79^{\circ}$ posicao, sendo essa posiçäo intermediára, visto que são avaliados 174 paises Fazendo cruzamentos estatísticos com dados do $I B G E$. Paixão fez um recorte nos dados do lDH e concluiu que, tomando por base apenas a populaçáo negra brasileira, a classificacão do Brasil iria para a 108 posiçáo. Tomando os dados da populacăo branca, o Brasi subiria para a $49^{\circ}$ posiça. o que evidencia uma diferença entre uma populacio e outra de 59 postcóes.

32 Universidade Federal de Alagoas.

33 A taxa de analfabetismo no País, segundo o IBGE, entre os brancos é de 10,6\%. entre os pardos de 25,3\% e chega a 28,7\% entre os negros (Fotha de Säo Paulo, 05 de junho de 2001, cademo Folha cotidiano, c4.) Os formados universitários, conforme o INEP Instituto Nacional de Estudos e Pesquisas Educacionais), em 2000. ficaram distribuidos da seguinte forma: $80 \%$ brancos, $2,2 \%$ negros 13.5\% pardos, $2.6 \%$ amarelose 1\% indigenas ou caboclos (Folna de Säo Paulo, 14 de janeiro de 2001. cademo Folha Cotidiano. c1)

34 Mesmo sendo atenuada na maioria dos casos. discriminação se mantém.

35 Acadêmica do $4^{\circ}$ ano de Nutriçäo, o nome é ficticio.

36 Acadêmico do $I^{\circ}$ ano de História, o nome é ficticio. 
"A escola peca muito mais por se omitir do que por manifestar alguma ação de racismo" (Jurandir ${ }^{37}$ ).

“Nos livros por exemplo, você não vê a figura de negros nos livros, você só vê a figura de negros em História quando se fala em escravidão, você não vê famílias negras representadas (...)." (Helena).

\section{"A escola peca muito mais por se omitir do que por manifestar alguma ação de racismo".}

Jurandir $^{37}$

37 Acadêmico do $4^{\circ}$ ano de Pedagogia, o nome é ficticio.

38 Acadêmica do $3^{\circ}$ ano de Psicologia, o nome é ficticio.

39 Acadêmico do $4^{\circ}$ ano de Psicologia, o nome é ficticio.

40 Acadêmico do $2^{\circ}$ ano de Agronomia, o nome éficticio.

$41 \dot{E}$ inerente à brincadeira a ambivalência (talvez o melhor termo seja polivalência) de sentidos.

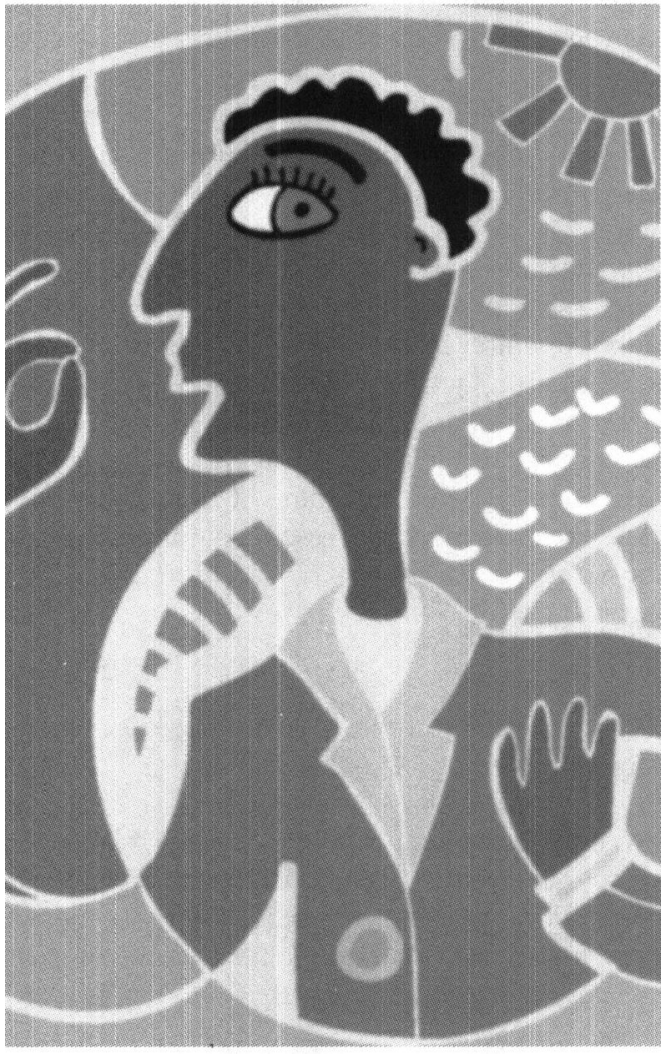

Nas relaçōes entre os companheiros escolares e os amigos de bairro, os processos discriminatórios apresentaram-se em três esferas: 1) brincadeiras, 2) tratamentos e 3) olhares. Porém, em todas essas esferas de manifestação do racismo encontramos em comum o fato de ele ser um tanto indireto mascarado ou subjetivo. Vale ressaltar que a manifestação desses comportamentos se apresentam, certamente (mas sem descartar outras razões), por haver certa omissão dos diversos setores da sociedade, inclua-se nisto a formação familiar, escolar e social. Essa omissão permite o reforço e a assimilação de determinados repertórios comportamentais que, numa avaliaçăo global, podem ser prejudiciais.

"Eu acho que assim, tem uma certa hipocrisia, uma coisa mascarada, mas existe, existe sim claro, eu acho que é forte ainda, (...) eu acho que existe, mas é de forma mascarada, mas existe $\operatorname{sim}^{\prime \prime}$ (Maria ${ }^{38}$ ).

"Eu sinto um certo preconceito, algumas pessoas me olham assim como se dissessem: 'o que é que esse negro, esse moreno tá fazendo na universidade, isso não é lugar pra ele, (...) é algo assim meio indireto"(João ${ }^{39}$.

"Eu não sei dizer muito como acontece não, a gente sabe que acontece, né? A gente sente que acontece, embutido, mascarado, mas sente que acontece"(Helena).

\section{As Brincadeiras}

Quando se especificam os casos de manifestação nas três esferas, encontramos uma riqueza de detalhes nos comportamentos discriminativos em nossa sociedade. A discriminação manifestada nas brincadeiras foi relatada por todos os entrevistados. Parece ser essa forma a mais comum e mais freqüente. Vale frisar que o termo brincadeira, aqui, não representa na íntegra o seu significado; essa manifestação discriminatória recebe esse nome por se apresentar em piadas, caricaturas, apelidos, além de muitas vezes partir de pessoas que possuem certa proximidade.

“(...) sempre tem alguém que brinque assim de forma, às vezes, até sem maldade. Às vezes, mas geralmente brinca porque você tem a pele mais escura do que o outro, porque o seu cabelo é mais duro, aquela coisa toda, que o seu nariz é diferente do outro, sempre tem esse tipo de... digamos brincadeira entre aspas, que pra mim não é brincadeira"(José).

"Brincam, no bairro, na escola. Brincam entre eles, mas pra mim aquilo é tortura. Hoje não, mas eu já senti muita vergonha de ser o que sou por causa das brincadeiras"(Juarez ${ }^{40}$ ).

“(...) ficam tirando brincadeiras, chamando apelidos, tipo: macaca, nega, preta, essas coisas assim" (Helena).

“Eu nunca fui vítima assim, você é negra e coisa do tipo, tem brincadeiras entre amigos que sempre tiram, mas eu nunca fui diretamente discriminada" (Maria).

O racismo apresentado sob forma de brincadeiras oferece inúmeras formas de defesa para o seu praticante. Um sujeito que se utilize das brincadeiras para discriminar pode recorrer a vários artifícios para se safar, pois as brincadeiras têm a possibilidade de serem interpretadas de diferentes modos. São uma categoria de comportamento útil para quem adquire. Por essa razão, a discriminação em nosso contexto pode ser declarada inteligente, visto que não perde a capacidade de ferir e denegrir, mas consegue se camuflar numa aparente inocente brincadeira ${ }^{41}$. 


\section{Os Olhares}

Mas, como já exposto, não é unicamente sob a forma de brincadeira que o racismo se torna concreto em nossa sociedade. Sob a forma de olhares, que denunciam um certo espanto, rejeição e insatisfação, também pudemos constatar discriminação no processo formativo de nossos universitários.

"Você nota que estão te olhando porque você é negro, porque não lhe querem ali. Você fica até meio encucado sem poder ter certeza se é realmente por isso, mas você procura outra razão e não encontra. Na verdade parece que os olhares estão gritando: 'sai daqui!'"' (Jurandir).

"Ninguém percebeu, mas eu percebi. Eles [um casal branco] estavam no shopping, a gente tava todo mundo sentado e eles perceberam. Assim, eles olhando, eu percebendo que (...) não estavam muito satisfeitos com a [minha] presença" (Juarez).

"(...) eu já sinto um olhar meio vesgo, um olhar meio troncho, por você ser negro e por você ser pobre. É como se dissesse: ‘você está no seu lugar, então, não tem pra que lhe dar atenção não tem pra que the dar uma chance, eu sinto isso'" (João).

"Você percebe que as pessoas estão olhando pra você como quem dizem: 'o que é que esse cara tá fazendo aqui? Porque não um branco.'"(José).

O olhar também é uma forma indireta, subjetiva, de discriminar. É uma forma não declarada. É percebido quase que unicamente pelos sujeitos que são vítimas. Sem dúvida os sujeitos vitimados pelos olhares discriminantes carregarão essas lembranças como marcas perenes que influenciarão condutas futuras.

\section{Os Tratamentos}

Uma outra forma de discriminação comum, no relato dos entrevistados, foi por meio de tratamentos involuntários e expontâneos que demonstram uma maneira diferente de perceber as pessoas em nosso ambiente. $\mathrm{Na}$ verdade, esse processo discriminatório só vem confirmar toda a ideologia racista existente no imaginário do alagoano e do brasileiro. Além disso, demonstra que o racismo brasileiro sem dúvida é diferente do dos demais países.

“(...) quando você entra numa loja, você e uma amiga, colega sua que é branca, você percebe que a vendedora vem atender a pessoa que é branca e nāo a você. Às vezes a pessoa tá indo me acompanhar, sendo eu que vou comprar, ai ela vai logo pra pessoa que tá comigo: 'deseja alguma coisa" (Helena).

"(...) se por um acaso, você disser uma coisa assim: vamos comigo em tal lugar, sem compromisso nenhum, só pra me acompanhar. A pessoa dá um jeito, até inconscientemente, e não vai"(José).

"Quando eu perguntei se estavam me tratando daquela forma [não queriam recebê-lo em uma peça de teatro] porque eu era negro, me disseram que não era por isso. Mas quando eu perguntei porquê era então, eles ficaram calados" (Jurandir).

\section{Considerações Finais}

Nosso racismo embora, seja uma realidade, não é declarado, não é assumido, não é confessado. Mas é concreto, e, dependendo da observação, visível. "(...) parece que o racismo é uma coisa que se sente, mas que não se comenta, principalmente quando se é criança. Eu acho que nunca foi falado sobre racismo numa sala de aula, eu não lembro, é uma coisa que todo mundo esconde (...). Mas a gente vê"(Helena).

Entretanto, o nosso racismo talvez traga até maiores prejuízos aos sujeitos que as demais formas de racismo. Nosso racismo gera insegurança, desprezo pela identidade pessoal, diminui a auto-estima dos sujeitos e traz marcas profundas para a sua personalidade, marcas que nem sempre lhe proporcionam crescimento. Marcas que devem ser melhor estudadas pela Psicologia.

Quando um dos entrevistados foi questionado sobre o seu sentimento em relação à sociedade brasileira, ele respondeu:

"Medo, sei lá, uma insegurança. Você nunca sabe porque é que estão lhe tratando bem, e você não sabe se aquela pessoa trata só você bem, e não trata os outros negros (...). É muito difícil viver numa sociedade mascarada, você nunca sabe" (José).

Os processos formais de ensino ainda se mostram omissos quanto à problemática que verificamos. A sociedade se apresenta conivente, de certa maneira, pois é uma ótima reprodutora desta ideologia injusta. Entretanto, vemos agora, mais que antes, o quanto é necessário repensarmos um projeto pedagógico diferente do modelo que temos atualmente.

Sabemos que essa forma de racismo apenas dificulta o seu combate e represália. Um racismo declarado e assumido permite uma rápida mobilização dos grupos discriminados para combater esse mal, porém um racismo "inteligente"

\section{Nosso racismo embora, seja uma realidade, não é declarado, nõo é assumido, nãoé confessado. Mas é concreto, e, dependendo da observaçõo, visível.}


e mascarado como o nosso nos deixa atônitos, pois temos a impressão de estar combatendo um mal inexistente, ou melhor, invisível.

É preciso, nesse sentido, a construção de um projeto pedagógico global, partindo de uma reflexão psicológica, para a sociedade brasileira, aberto à diversidade cultural e democrática.

Entretanto, sabemos que a escola, com o auxílio de pesquisas psicológicas, pode e deve contribuir de forma mais enfática e reflexiva nesse processo, tendo em vista que é a escola por excelência a principal responsável pela formação dos futuros cidadãos $^{42}$. Esperamos ter ficado evidente a necessidade de maior reflexão sobre os processos formativos de nossa identidade cultural. Somente com essa reflexão poderemos construir uma sociedade mais justa e igualitária, em que a "democracia racial" possa realmente se tornar uma realidade e os sujeitos possam se considerar mais seguros independentemente de sua etnicidade.
42 Temos plena convição de que a omissão existente nas escolas e na sociedade com relação ao racismo nada contribui para a superação do problema das relaçōes raciais na sociedade brasileira.

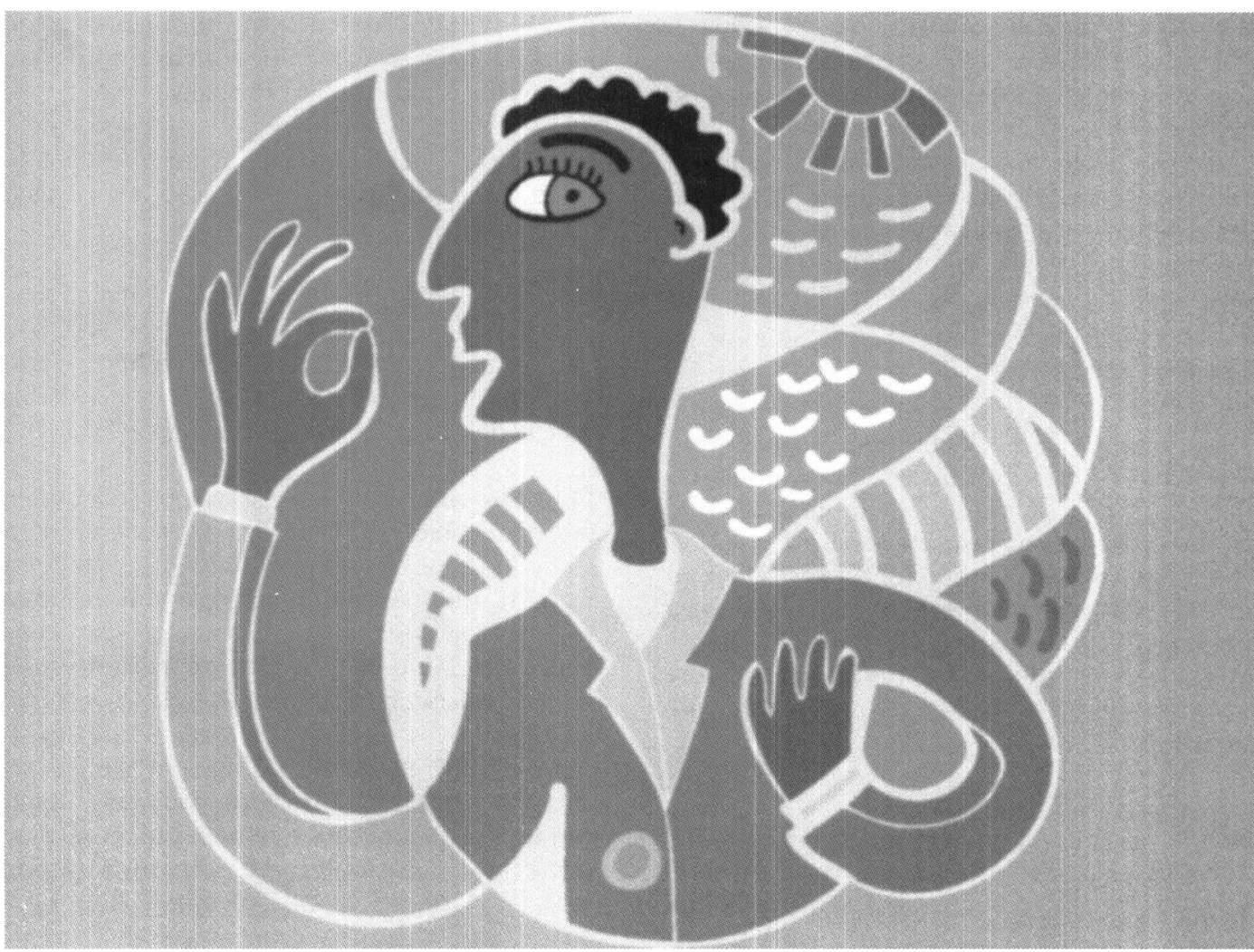




\section{Cerson Alves da Siha Júnior \\ Rua $H, 128$ Conj. H. Equelman,- \\ Antares - Maceio - Alagoas - 57084-030 \\ E-mail: tamuia@hotmail.com \\ Tel.: (82) 334-1826}

Recebido 07/05/02 Aprovado 16/08/02

Alves, E. As Diferentes Concepções de Multiculturalismo: uma Experiência no Ensino de Arte. In: Pátio. Ano. 02, n. 06. Porto Alegre: Artmed. Agos/out.98.

Benjamin, W. Sobre o Conceito de História. In: Magia e Técnica, Arte e Politica: Ensaios sobre Literatura e História da Cultura. 7 ed. São Paulo: Brasiliense, 1994. (Obras escolhidas; v.1)

Cavalleiro, E. S. Raça e Educação Infantil: Produção da Submissāo Social In: ICONGRESSO BRASILEIRO DE PESOUISADORES NEGROS, 2000 , Recife, mime.

Chizzotti, A. (1995). Pesquisa em Ciências Humanas e Sociais. 2. ed. Sāo Paulo: Cortez.

Costa, M. V. (1998).Currículo e Política Cultural. In: O Currículo nos Limiares do Contemporâneo. Rio de Janeiro: DP\&A.

Cunha JR, H.(1998). Afrodescendência, Pluriculturalismo, e Educação In: Pátio, ano 2, nº6, pp. 21-24.

, Afrodescendência, Pluriculturalismo e Educação. In: Educação, Sociedade \& Culturas. n. 10, Porto: Afrontamento. out. 98

Featherstone, M. (1997). O desmanche da Cultura - Clobalização. Pósmodernismo e Identidade. São Paulo: Studio Nobel: SESC. (Coleção Megalópoles).

Fredrickson, G. M. (1995).Uma História Comparada do Racismo: Reflexōes Gerais. In:: WIEVIORKA, Michel (org.). Racismo e Modernidade. Tradução Luís de Barros. Portugal: Bertrand, p. 44-55.

Gagnebin, J. (1994). Prefácio - Walter Benjamin ou a História Aberta. In: WALTER, Benjamin. Magia e Técnica, Arte e Politica: Ensaios Sobre Literatura e História da Cultura. 7.ed. São Paulo: (Obras Escolhidas;v.1)

Geertz, C. (1997).Mistura de Gêneros: a reconfiguração do pensamento social. In: O saber local: novos ensaios em antropologia interpretativa. Petrópolis,RJ: Vozes.

Comes, R.(1985). Crítica da Razão Tupiniquim. 7.ed. Porto Alegre: Mercado aberto.

Hunt, L. (1992). A Nova História Cultural. São Paulo: Martins Fontes.

Lane, S. T. M. \& Codo, W . (1998).(orgs) Psicologia Social; o Homem em Movimento. Rio Grande do Sul: Brasiliense.

Lopes, D. L. (2000). Mobilidade Social e Identidade Racial: o Negro na Perspectiva do Ensino Superior. In: I CONGRESSO BRASILEIRO DE PESQUISADORES NECROS, Recife, mime.

Marrach, S. Alem. (1998). O Lúdico, o Riso e a Educação no Romance de François Rabelais. Ensaios da F.F.C.. n.2. Marília, SP: UNESP.

Marrow, R. Allen \& Torres, C. A.(1997). A Teoria Crítica e a Educação: da Escola de Frankfurt ao Pós-estruturalismo In: Teoria Social e Educação. Porto: Afrontamento.
\& Habermas, 1., Paulo Freire e a Pedagogia Crítica: Novas Orientaçōes para a Educação Comparada. In: Educação, Sociedade \& Culturas. n. 10, Porto: Afrontamento. out 98

Mclaren, P. (1997).Multiculturalismo Critico. São Paulo: Cortez.

Munanga, K. (1996). Mestiçageme Experiências interculturais no Brasil. In: Schawarcz, Lilia Moritz, REIS, Leticia de Souza (orgs.) Negras Imagens. São Paulo: Editora da Universidade de São Paulo: Estação Ciência.

Munanga, K. (1999). Rediscutindo a Mestiçagem no Brasil: Identidade Nacional Versus Identidade Negra. Petrópolis: Vozes.

Pettigrew, T. F. \& Meertens, R. W. (1995).Racismo Velado: Dimensōes e Medidas. In: WIEVIORKA, Michel (org.). Racismo e Modernidade. Tradução Luís de Barros. Portugal: Bertrand, p. 110-128.

Santana, M. de M. Olodum - Curricularidade em Ritmo de SambaReggae - Carnavalizando a Educação. Tese de doutorado. São Paulo: Programa de Pós-graduação em Educação-Currículo, PUC, 2000.

Schwarcz, L. M.(1993). Oespetáculo da miscigenação: cientistas, instituições e questões raciais no Brasil - 1870-7930. Sāo Paulo: Companhia das Letras.

Skinner, B. F. (1957).Verbal Behavior, New York, Appleton Century Crofts.

Skinner, B. F. (1969). Contingencies of Reinforcement: A theoretical analysis, New York, Appleton Century Crofts.

Skinner, B. F. (1974)About Behaviorism, New York: Alfred A. Knopf.

Silva, K. E. O. da. (2001). O Papel do Direito Penal no Enfrentamento da Discriminaçāo. Porto Alegre: Livraria do Advogado.

Silva, T. T. da.(1993). Sociologia da Educaçāo em Tempos Pós-modernos. In: Teoria Crítica em Tempos Pós-modernos. Porto Alegre: Artes Médicas.

(1995).Curriculo e Identidade Social: Territórios Contestados. In: Silva, T. T. (org.). Aienígenas na sala de aula - uma introdução aos estudos culturais em educaçāo. Petrópolis: Vozes.

Souza, F. M. do N.( 2000). Influência da Escola no Desenvolvimento da Auto-Estima de Alunos Negros Pré-adolescentes. In: I CONCRESSO BRASILEIRO DE PESQUISADORFS NECROS, Recife, mime

Sundiata, I.(1996). Repensando o Africanismo da Diáspora. In: Munanga, Kabengele (org.). Estratégias e Políticas de Combate à Discriminação Racial. São Paulo: EDUSP/Estação Ciência.

Wagner, U. (1995) A Influência da Classificação Social. In: WIEVIORKA, Michel (org.). Racismo e Modernidade. Tradução Luís de Barros. Portugal: Bertrand. p. 137-147.

Wieviorka, M.(1995). (org.). Racismo e modemidade. Tradução Luís de Barros. Portugal: Bertrand

\section{Referências bibliográficas}

